\title{
Influence of Yoga-Based Personality Development Program on Psychomotor Performance and Self-efficacy in School Children
}

\author{
Madhusudan Das, Singh Deepeshwar*, Pailoor Subramanya and \\ Nandi Krishnamurthy Manjunath
}

Yoga and Life Sciences Laboratory, Swami Vivekananada Yoga Research Foundation, Bangalore, India

Selective attention and efficacy are important components of scholastic performance in school children. While attempts are being made to introduce new methods to improve academic performance either as part of curricular or extracurricular activities in schools, the success rates are minimal. Hence, this study assessed the effect of yoga-based intervention on psychomotor performance and self-efficacy in school children. Two hundred ten school children with ages ranging from 11 to 16 years (mean age \pm SD; $13.7 \pm 0.8$ years) satisfying the inclusion and exclusion criteria were recruited for the 10-day yogä program. An equal number of age-matched participants $(n=210$; mean \pm SD; $13.1 \pm 0.8$ years) were selected for the control group. Participants were assessed for attention and performance at the beginning and end of 10 days using trail making task (TMT) A and B, and self-efficacy questionnaire. The yoga group showed higher self-efficacy and improved performance after 10 days of yoga intervention. The performance in TMT-A and -B of the yoga group showed a significantly higher number of attempts with a reduction in time taken to complete the task and a number of wrong attempts compared with control group. Results suggest that yoga practice enhances self-efficacy and processing speed with fine motor coordination, visual-motor integration, visual perception, planning ability, and cognitive performance.

Specialty section:

This article was submitted to Child and Adolescent Psychiatry,

a section of the journal

Frontiers in Pediatrics

Received: 29 March 2015 Accepted: 30 May 2016

Published: 15 June 2016

Citation:

Das M, Deepeshwar S, Subramanya $P$ and Manjunath NK (2016) Influence of Yoga-Based Personality Development Program on Psychomotor Performance and Self-efficacy in School Children.

Front. Pediatr. 4:62. doi: 10.3389/fped.2016.00062

\section{INTRODUCTION}

Scholastic performance in school children depends on multiple factors. Memory, attention, and motor speed are some of the important intrinsic factors, which play a major role in an individual's performance. Motivation to perform can also be influenced by self-efficacy (1). Self-efficacy is defined as "an individual's judgment of his/her own capabilities to organize and execute the tasks to achieve optimal performance" (2). High self-efficacy is related to a number of positive physical, social, and psychological outcomes. A longitudinal study of 390 adolescents, reported lower levels of depression and delinquency with positively correlated emotional self-efficacy (the perceived ability to handle negative emotions and express positive emotions) (3). Another study on low self-efficacy in students and patients reported severity of social anxiety and associated social impairment (4). Therefore, attempts are being made to create structured activities within the curriculum, which can enhance an individual's scholastic behavior and performance. But, these programs with focused 
objectives have resulted in improvement of the student's performance, but not behavior.

Yoga is an ancient Indian discipline that aims at developing an integrated personality, where the growth of physical, mental, social, and spiritual planes is equally focused $(5,6)$. Manjunath and Telles reported that practicing yoga (including postures, regulated breathing, relaxation techniques, and meditation) can improve the ability to plan and execute a given cognitive task in school children (7). Furthermore, several studies have demonstrated the positive impact of yoga in terms of enhanced attention, concentration, and memory (visual and spatial memory) $(8,9)$ in school children. It was demonstrated that the combination of yoga practices can improve motor speed (10), while an individual technique (called cyclic meditation) involving focused attention can improve perception (11).

In addition, the beneficial effects of yoga in improving hand steadiness, which is suggestive of better attention and concentration (8) has been documented. Furthermore, a recent report suggested an improvement in motor skills and visual discrimination following the practice of a yoga-based breathing technique (Kapalabhati), compared with breath awareness (12).

It is evident from these earlier studies that combination of yoga practices in general, and selected individual yoga techniques in isolation, can positively influence an individual's perception and motor performance. The studies mentioned above provide some evidence for the use of yoga in improving motor function, attention, and perception, which are important for scholastic performance. However, there are no comprehensive studies with larger sample size, controlled environment, and longer duration of intervention available to understand the influence of a customized yoga module on an individual's performance and behavior.

Hence, this study was designed to evaluate changes in psychomotor performance and self-efficacy following a specially designed personality development yoga camp for school children.

\section{MATERIALS AND METHODS}

\section{Participants}

Four hundred twenty healthy school children with ages ranging between 13 and 16 years were recruited. Two hundred ten children $(\mathrm{M}=13.78$; $\mathrm{SD}=0.89)$ were from a self-selected 10-day yoga-based "Personality Development Camp" (PDC) at a yoga institution, in South India. An equal number of age-matched subjects $(M=13.08 ; S D=0.84)$ without any experience of yoga were selected as control group from a school within the same locality. The inclusion criteria included (i) between 13 and 16 years of age, (ii) English as the medium of instruction in the school, (iii) willingness to participate in the study, and (iv) no hospitalization in the last 3 months. The exclusion criteria included (i) any history of neurological or psychiatric disturbances and (ii) learning disability if any (i.e., slow learner). The study was approved by the Institutional Ethics Committee (Res/IEC-SVYASA/003/2013) of the yoga institution. Since the selected age group included minors (below 18 years of age), signed informed consent was obtained from their parents and guardian (Principal of the School). Demographic details of the participants are given in Table $\mathbf{1}$.
TABLE 1 | Characteristics of the participants.

\begin{tabular}{|c|c|c|c|c|}
\hline \multirow[t]{2}{*}{ Participants } & \multicolumn{2}{|c|}{ Yoga group } & \multicolumn{2}{|c|}{ Control group } \\
\hline & $n$ & $M \pm S D$ & $n$ & $M \pm S D$ \\
\hline Age (years) & 210 & $13.78 \pm 0.89$ & 210 & $13.08 \pm 0.84$ \\
\hline \multicolumn{5}{|l|}{ Gender } \\
\hline Male & 140 & $13.75 \pm 0.91$ & 124 & $13.18 \pm 0.83$ \\
\hline Female & 70 & $13.84 \pm 0.88$ & 86 & $12.93 \pm 0.83$ \\
\hline \multicolumn{5}{|c|}{ Socioeconomic status } \\
\hline High & 48 (23\%) & & 32 (15.24\%) & \\
\hline Middle & 148 (70.5\%) & & 162 (77.14\%) & \\
\hline Lower & $14(6.5 \%)$ & & $6(6.7 \%)$ & \\
\hline \multicolumn{5}{|c|}{ Educational status } \\
\hline Up to 6 years & 52 (24.76\%) & & 63 (30\%) & \\
\hline Up to 8 years & 123 (58.57\%) & & 119 (56.67\%) & \\
\hline Up to 10 years & 35 (16.67\%) & & $28(13.33 \%)$ & \\
\hline
\end{tabular}

\section{Design}

Eligible subjects from the PDC camp at the yoga institution who were willing to participate in the study were stratified based on age and academic status and were assigned to the yoga group. The yoga group and the control group were assessed before and immediately after 10 days. They were assessed similar to the experimental group on days 1 and 10 during which time the subjects were asked to continue with their normal routine.

\section{Intervention}

The 10-day "Personality Development Camp" (PDC) of $10 \mathrm{~h}$ per day was designed for children below 17 years of age. The 10-h routine consisted of physical postures (Asanas), voluntary regulated breathing (Pranayama), meditation (Dhyana), relaxation techniques, internal cleansing practices (Kriyas), and reciting hymns from traditional yoga texts, music, yoga games, and happy assembly. Kriyas are yogic cleansing exercises, which are performed to cleanse the body and assist with the natural removal of waste products (13). Details of the intervention are summarized in Table 2.

\section{Assessments}

Each subject was assessed in two sessions, one using trail making tasks-A and -B (TMT) (14) and the second using self-efficacy questionnaire for children (SEQ-C) (15). Although trail making tasks are very simple, it has been hypothesized that they reflect various cognitive processes including attention, visual search and scanning, sequencing and shifting, psychomotor speed, abstraction, flexibility, ability to execute and modify a plan of action, and ability to maintain two trains of thoughts simultaneously (12).

During the TMT session, subjects were assessed individually by seating them on a comfortable chair. Trail making task "A" involved subjects drawing lines connecting 25 consecutive circled numbers in a numerical sequence (i.e., 1-2-3, etc.) as rapidly as possible. In task " $B$," the subjects were directed to draw lines to connect 12 consecutive circled numbers and 12 consecutive letters in an alternate numeric and alphabetic sequence (i.e., 1-A-2-B, etc.) as rapidly as possible. Time (in seconds) taken for completing the task was noted by using a stop watch. 
TABLE 2 | Summarized 10-day Yoga intervention program.

\begin{tabular}{|c|c|c|}
\hline SI no. & Name of intervention & Duration \\
\hline 1. & $\begin{array}{l}\text { Asana session } \\
\text { - Standing posture } \\
\text { - Sitting postures } \\
\text { - Prone posture } \\
\text { - Inverted postures } \\
\text { - Supine postures }\end{array}$ & $2 \mathrm{~h}$ \\
\hline 2. & $\begin{array}{l}\text { Pranayama session } \\
\text { - Sectional breathing } \\
\text { - Thoracic breathing } \\
\text { - Diaphragm breathing } \\
\text { - Hyperventilation (Bhastrika and Kapalbhati) } \\
\text { - Balancing of the breath (NadiShuddhi, AnulomVilom) }\end{array}$ & $1 \mathrm{~h}$ \\
\hline 3. & $\begin{array}{l}\text { Cleansing techniques (Kriyas) } \\
\text { - Trataka (eye-cleansing techniques) } \\
\text { - Sutra Neti and JalaNeti (nasal tract-cleansing } \\
\text { techniques) } \\
\text { - VamanDhouti and LaghuShankaPrakshalana } \\
\text { (Gl tract-cleansing techniques) }\end{array}$ & Twice \\
\hline 4. & $\begin{array}{l}\text { Gita Chanting session } \\
\text { - Chanting (18 verses from Bhagavad Gita) } \\
\text { - Yogic discourse }\end{array}$ & $1 \mathrm{~h}$ \\
\hline 5. & $\begin{array}{l}\text { Creativity hour } \\
\text { - Karma yoga } \\
\text { - Designing and arts } \\
\text { - Tree plantation } \\
\text { - Debate } \\
\text { - Stories }\end{array}$ & $2 \mathrm{~h}$ \\
\hline 6. & $\begin{array}{l}\text { Bhajan session } \\
\text { - Devotional songs } \\
\text { - Patriotic songs }\end{array}$ & $1 \mathrm{~h}$ \\
\hline 7. & $\begin{array}{l}\text { Game session } \\
\text { - Yogic games } \\
\text { - Group awareness }\end{array}$ & $1 \mathrm{~h}$ \\
\hline 8. & $\begin{array}{l}\text { Happy assembly } \\
\text { - Cultural program } \\
\text { - Team work }\end{array}$ & $2 \mathrm{~h}$ \\
\hline
\end{tabular}

The errors committed during the task completion were scored removing accurately (16).

Self-efficacy questionnaire for children was developed by Muris (15) to assess general self-efficacy across three domains: academic, social, and emotional situations. The SEQ-C is a 24-item self-reported measure with eight items for each domain. Each item is rated on a 5-point Likert scale with 1 being "not at all" and 5 being "very well." Both assessments were arranged on separate days at the same time for the two groups (i.e., Yoga and Control). The SEQ-C was administered as a group test, and the subjects were seated comfortably.

\section{Procedure}

The TMT and self-efficacy questionnaire (SEQs) questionnaires were administered on children of both the groups (yoga and control) on Day 1 and Day 10 of personality development yoga camp. The data collection lasted for $20 \mathrm{~min}$. The yoga groups underwent for 10 days yoga practices, whereas control group were asked to continue with their normal routine. The yoga educator was blind to the hypothesis of the study. After 10 days of yoga intervention, all children were asked to complete the same questionnaires. The researchers explained about the study and gave stipulated instructions of the manuals to children for better understanding. Children were not given feedback as to their performance on designing experiments or any of the measures.

While data extraction, TMT scores were extracted based on wrong attempts, right attempts, and total attempts to see the error affect of the children. The extraction of TMT also included the completion time for the task, i.e., time duration in seconds. The SEQ-C was extracted based on the responses on three domains of self-efficacy, i.e., (i) social self-efficacy, which has to do with the perceived capability for peer relationship and assertiveness; (ii) academic self-efficacy, which is concerned with the perceived capability to manage one's own learning behavior, to master academic subjects, and to fulfill academic expectations; and (iii) emotional self-efficacy, which pertains to the perceived capability of coping with negative emotions.

\section{Data Analysis}

The raw data were obtained from Trail Making Tasks A and B as well as SEQ and tabulated separately. The raw data were analyzed using Statistical Package for Social Science (SPSS) Version 20. Data of different variables were tested with the KolmogorovSmirnov test for normality. Since, we had two Groups, i.e., yoga and control, and two states, i.e., day 1 and day 10, repeated measures analysis of variance (RM-ANOVA) was carried out for each assessment. For Trail making tasks (A and B), RM-ANOVA was performed with one "Within-subjects" factor, i.e., state (day 1 and day 10), which in turn had four subdomains (wrong attempt, right attempt, total attempt, and time taken) and one "Betweensubjects" factor, i.e., groups (yoga and control). Similarly, for self-efficacy, RM-ANOVA was performed with one "Withinsubjects" factor, i.e., states (day 1 and day 10), which in turn had three subdomains (academic, social, and emotional) and one "Between-subjects" factor, i.e., groups (yoga and control). This was followed by a pairwise comparison between the mean values of day 1 and day 10 assessments with Bonferroni correction. The alpha level was set at $p<0.05$.

\section{RESULTS}

\section{TMT}

For Trail making task "A" (TMT-A), the repeated measures ANOVA showed a significant difference for Between-subjects factor, i.e., groups $\left[F_{(1,418)}=12.38 ; p<0.001 ; \eta^{2} p=0.029\right]$ as well as for Within-subjects factor, i.e., states $\left[F_{(3,1254)}=2164.29 ; p<0.001\right.$; $\left.\eta^{2} p=0.84\right]$ and for sub domains of TMT-A assessments, i.e., wrong attempt $\left[F_{(1,418)}=29.45 ; p<0.001 ; \eta^{2} p=0.06\right]$, right attempt $\left[F_{(1,418)}=30.10 ; p<0.001 ; \eta^{2} p=0.07\right]$, total attempt $\left[F_{(1,418)}=0.55\right.$; $\left.p>0.05 ; \eta^{2} p=0.001\right]$, and time taken $\left[F_{(1,418)}=58.83 ; p<0.001 ;\right.$ $\left.\eta^{2} p=0.13\right]$. The interaction between subdomains of TMT assessments $\times$ groups $\left[F_{(3,1254)}=12.24 ; p<0.001 ; \eta^{2} p=0.028\right]$ and State $\times$ Groups $\left[F_{(1,418)}=61.24 ; p<0.001 ; \eta^{2} p=0.13\right]$ were also significant.

After 10 days, in the Trail making task "A" (TMT-A), pairwise comparisons with Bonferroni correction showed a significant increase in the "right attempt" scores $(p<0.001)$ with the 
reduction in the "wrong attempt" scores $(p<0.001)$ in the yoga group, while there was no difference in the control group. Also, the "total numbers" attempted were significantly higher $(p<0.05)$ and the "time taken" was significantly lower $(p<0.001)$ in the yoga group compared with control group.

Similarly, for Trail making task-B (TMT-B), the repeated measures ANOVA showed a significant difference in "Betweensubjects" factor, i.e., groups $\left[F_{(1,418)}=12.38 ; p<0.001\right.$; $\left.\eta^{2} p=0.029\right]$ as well as for "Within-subjects" factor, i.e., states $\left[F_{(3,1254)}=2164.29 ; p<0.001 ; \eta^{2} p=0.84\right]$, and for sub domain of TMT-B assessments, i.e., wrong attempt $\left[F_{(1,418)}=28.91\right.$; $\left.p<0.001 ; \eta^{2} p=0.06\right]$, right attempt $\left[F_{(1,418)}=29.7 ; p<0.001 ;\right.$ $\left.\eta^{2} p=0.07\right]$, total attempt $\left[F_{(1,418)}=1.01 ; p>0.05 ; \eta^{2} p=0.002\right]$, and time taken $\left[F_{(1,418)}=66.19 ; p=0.001 ; \eta^{2} p=0.14\right]$. The interaction between TMT-B assessments $\times$ groups $\left[F_{(3,1254)}=12.24 ; p<0.001\right.$; $\left.\eta^{2} p=0.028\right]$ and state $\times$ groups $\left[F_{(1,418)}=61.24 ; p<0.001 ;\right.$ $\left.\eta^{2} p=0.13\right]$ was also significant.

Pairwise comparisons between mean values of the yoga group showed a significant increase in the scores of "right attempts" $(p<0.001)$ with the reduction of "wrong attempts" $(p<0.001)$. Additionally, yoga practices, improved "total attempts" $(p<0.001)$ with the reduction in the time taken $(p<0.001)$. On the other hand, there were no significant changes in the control group $(p>0.05)$ scores of day 1 to day 10 . The group mean values, SD, median, and interquartile range of trail making task (A and B) of both the groups on day 1 and day 10 are given in Table 3 .

\section{Self-efficacy}

For self-efficacy, the repeated measures ANOVA showed a significant difference "Between-subjects" factor, i.e., groups $\left[F_{(1,418)}=18.94 ; p<0.001 ; \eta^{2} p=0.043\right]$ and states $\left[F_{(1,418)}=181.29\right.$; $\left.p<0.001 ; \eta^{2} p=0.30\right]$. The test of Within-subjects effect showed that there were significant interaction between states $\times$ groups $\left[F_{(1,418)}=119.13 ; p<0.001 ; \eta^{2} p=0.22\right]$ and subdomains of assessments $\times$ states $\left[F_{(3,1254)}=107.02 ; p<0.001 ; \eta^{2} p=0.20\right]$.

The pairwise comparisons with Bonferroni correction for the yoga group showed a significant increase in the scores of academic domains $(p<0.001)$, the social domain $(p<0.001)$, and emotional domain $(p<0.001)$, whereas there were no significant changes in the scores of the control group on day 1 to day 10 . The group mean values, SD, median, and interquartile range of the SEQ of both the groups on day 1 and day 10 with percentage change (\%) are given in Table 4.

The partial correlation showed that there was a significant inverse relationship between total self-efficacy score and the time duration of the test in Trial A $(r=-0.41 ; p=0.04)$ and in Trial $\mathrm{B}(r=-0.21 ; p=0.003)$ of $y o g a$ group, which suggest that with increasing self-efficacy, the duration of the test was reduced in

TABLE 3 | The groups mean values \pm SD of the trail making task (TMT) A and B for yoga and control groups in two states (pre and post).

\begin{tabular}{|c|c|c|c|c|c|c|c|c|c|}
\hline Assessments & Variables & Groups & $\begin{array}{l}\text { Pre } M \pm S D \\
\text { (median) }\end{array}$ & $\begin{array}{l}\text { Post } M \pm S D \\
\text { (median) }\end{array}$ & $\begin{array}{l}\text { Pre Interquartile } \\
\text { range }\end{array}$ & $\begin{array}{l}\text { Post Interquartile } \\
\text { range }\end{array}$ & $\begin{array}{c}\% \\
\text { Change }\end{array}$ & $\mathbf{T}$ & $p$-Values \\
\hline \multirow{8}{*}{$\begin{array}{l}\text { Trail making } \\
\text { task A }\end{array}$} & \multirow{2}{*}{$\begin{array}{l}\text { Wrong } \\
\text { attempt }\end{array}$} & Yoga & $0.61 \pm 1.26(0)$ & $0.05 \pm 0.26(0)$ & 1 & 0 & 91.80 & 6.396 & 0.000 \\
\hline & & Control & $1.14 \pm 1.88(0)$ & $0.46 \pm 1.01(0)$ & 1 & 0 & 59.65 & 5.000 & 0.000 \\
\hline & \multirow{2}{*}{$\begin{array}{l}\text { Right } \\
\text { attempt }\end{array}$} & Yoga & $24.39 \pm 1.25(25)$ & $24.95 \pm 0.26(25)$ & 1 & 0 & 2.30 & -6.379 & 0.000 \\
\hline & & Control & $22.87 \pm 1.87(25)$ & $23.54 \pm 1.01(25)$ & 1 & 0 & 2.93 & -4.934 & 0.000 \\
\hline & \multirow{2}{*}{$\begin{array}{l}\text { Total } \\
\text { attempt }\end{array}$} & Yoga & $24.88 \pm 0.76(25)$ & $25.00 \pm 0.07(25)$ & 0 & 0 & 0.48 & -2.239 & 0.026 \\
\hline & & Control & $23.91 \pm 0.60(25)$ & $23.95 \pm 0.44(25)$ & 0 & 0 & 0.17 & -0.736 & 0.463 \\
\hline & \multirow{2}{*}{$\begin{array}{l}\text { Time } \\
\text { duration (s) }\end{array}$} & Yoga & $35.92 \pm 17.43(32)$ & $26.48 \pm 9.88(25)$ & 11.5 & 10 & 26.28 & 11.128 & 0.000 \\
\hline & & Control & $62.84 \pm 26.99$ & $64.23 \pm 22.30$ & 18 & 16 & 2.21 & -1.441 & 0.151 \\
\hline \multirow{8}{*}{$\begin{array}{l}\text { Trail making } \\
\text { task B }\end{array}$} & \multirow{2}{*}{$\begin{array}{l}\text { Wrong } \\
\text { attempt }\end{array}$} & Yoga & $1.20 \pm 2.27(0)$ & $0.07 \pm 0.31(0)$ & 2 & 0 & 94.17 & 7.329 & 0.000 \\
\hline & & Control & $0.51 \pm 0.94(0)$ & $0.36 \pm 0.80(0)$ & 2 & 0 & 29.41 & 1.836 & 0.068 \\
\hline & \multirow{2}{*}{$\begin{array}{l}\text { Right } \\
\text { attempt }\end{array}$} & Yoga & $22.82 \pm 2.26(24)$ & $23.94 \pm 0.31(24)$ & 2 & 0 & 4.91 & -7.265 & 0.000 \\
\hline & & Control & $24.50 \pm 0.93(24)$ & $24.63 \pm 0.80(24)$ & 2 & 0 & 0.53 & -1.731 & 0.085 \\
\hline & \multirow{2}{*}{$\begin{array}{l}\text { Total } \\
\text { attempt }\end{array}$} & Yoga & $23.73 \pm 0.98(24)$ & $23.98 \pm 0.19(24)$ & 0 & 0 & 1.05 & -3.722 & 0.000 \\
\hline & & Control & $24.93 \pm 0.54(24)$ & $25.00 \pm 0.07(24)$ & 0 & 0 & 0.28 & -1.672 & 0.096 \\
\hline & \multirow{2}{*}{$\begin{array}{l}\text { Time } \\
\text { duration (s) }\end{array}$} & Yoga & $72.03 \pm 28.38(68)$ & $48.98 \pm 15.21(47)$ & 35.5 & 19 & 32.00 & 13.853 & 0.000 \\
\hline & & Control & $36.23 \pm 13.38(58)$ & $34.72 \pm 11.87(60)$ & 30 & 31 & 4.17 & 3.118 & 0.002 \\
\hline
\end{tabular}

TABLE 4 | Descriptive statistics groups mean values \pm SD of the self-efficacy questionnaire for yoga and control groups in two states (pre and post).

\begin{tabular}{|c|c|c|c|c|c|c|c|c|c|}
\hline Assessments & Variables & Groups & $\begin{array}{c}\text { Pre } \\
M \pm S D \\
\text { (median) }\end{array}$ & $\begin{array}{c}\text { Post } \\
M \pm S D \\
\text { (median) }\end{array}$ & $\begin{array}{c}\text { Pre } \\
\text { Interquartile } \\
\text { range }\end{array}$ & $\begin{array}{c}\text { Post } \\
\text { Interquartile } \\
\text { range }\end{array}$ & $\begin{array}{c}\% \\
\text { Change }\end{array}$ & $T$ & $p$-Values \\
\hline \multirow{8}{*}{$\begin{array}{l}\text { Self-efficacy } \\
\text { questionnaire } \\
\text { (SEQ) }\end{array}$} & \multirow{2}{*}{$\begin{array}{l}\text { Academic } \\
\text { domain }\end{array}$} & Yoga & $25.51 \pm 7.12(25)$ & $29.71 \pm 5.11(30)$ & 11 & 6 & 15.95 & -7.108 & 0.000 \\
\hline & & Control & $30.10 \pm 6.44(32)$ & $30.46 \pm 6.15(32)$ & 10 & 10 & 1.19 & -1.754 & 0.081 \\
\hline & \multirow[t]{2}{*}{ Social domain } & Yoga & $24.00 \pm 5.94(23)$ & $28.86 \pm 4.63(29)$ & 8 & 6 & 20.25 & -10.495 & 0.000 \\
\hline & & Control & $27.79 \pm 5.48(28)$ & $28.36 \pm 5.25(29)$ & 8 & 7 & 2.05 & -2.947 & 0.004 \\
\hline & \multirow{2}{*}{$\begin{array}{l}\text { Emotional } \\
\text { domain }\end{array}$} & Yoga & $22.26 \pm 5.65(21)$ & $27.98 \pm 5.00(28)$ & 7.3 & 7 & 25.70 & -13.173 & 0.000 \\
\hline & & Control & $25.56 \pm 5.20(25)$ & $26.19 \pm 4.95(26)$ & 7.3 & 7 & 2.46 & -3.318 & 0.001 \\
\hline & \multirow[t]{2}{*}{ Total score } & Yoga & $71.96 \pm 15.68(70)$ & $86.66 \pm 11.10(86)$ & 21 & 13 & 20.43 & -12.725 & 0.000 \\
\hline & & Control & $83.49 \pm 14.69(84)$ & $85.04 \pm 14.01(85)$ & 22 & 21 & 1.86 & -3.812 & 0.000 \\
\hline
\end{tabular}


trial A and trial B compared with the control group. This suggests that the self-efficacy was higher in yoga group with improved performance as compared with control group.

\section{DISCUSSION}

The results of this study revealed that the school children who performed regular yoga practices showed higher self-efficacy and improved performance compared with control group who continued with their normal routine. It also showed a positive relationship between self-efficacy and performance after adjusting for age, gender, and education levels in yoga group.

Self-efficacy and executive functions, especially motor performance, play a major role in the scholastic behavior of an individual. Self-efficacy in an individual measures the confidence and ability to execute specific behavior. It suggests that high self-efficacy motivates proactive behavior (17). Hence, this study made an attempt to understand the changes in different dimensions of self-efficacy and executive functions (based on a trail making task).

Our results are consistent with the earlier studies that 10-day yoga practice improves visual perception (7) with significant decrease in the number of errors in repeated trials $(10,18)$. Previous studies demonstrated that the daily yoga intervention has a significant impact on key classroom behaviors $(19,20)$ and improvement in academic performance, especially reading, as well as social and peer interactions in most of the children $(21,22)$. Berger et al. demonstrated that yoga had sustained effects with improvements in behavior, especially in the child's ability to pay attention in class, organizational skills with homework, and decreased impulsive behavior $(23,24)$. Recently, a long-term study showed a reduction in time taken to complete neurocognitive tasks after practicing vihangam yoga meditation in school children and also suggested that meditation improves mental functions, such as attention span (25), processing speed, attention alternation ability, and performance (26). This may be due to functional reorganization of brain activity patterns for focused attention and cognitive monitoring that takes place with mental practice, and this meditation-related changes are crucially associated to a functional reorganization of activity patterns in prefrontal cortex and in the insula (27). Yogic relaxation and meditation techniques have been shown to improve information processing speed $(26,28)$ in practitioners. In the context of attention, the TMT have been suggested to tap more complex attention or information processing, immediate memory and performance on recall capacity $(29,30)$ after yoga practice. Telles et al. studied 90 school children (45 in 2 groups) with ages ranging between 9 and 13 years and reported improvement in static motor performance (31) and a significant improvement in motor speed task on 53 adults and 152 children (10) after 10 days yoga intervention. A systematic review article mentioned that yoga and meditation intervention nurture mindfulness and may be a feasible and effective method of building resilience in childhood and adolescence (32). Fifty-seven healthy male adult volunteers showed significant improvements in psychomotor task performance (33 34), attention span, processing speed, attention alternation ability, and performance in interference tests (26) after yoga practices. Yoga may be an effective method to increase awareness and performance in cognitive, emotional, or social behavior (35). Our results are in concurrence with the above studies. All above mentioned studies have a common limitation, i.e., small sample size (21-24), suggesting less statistical power, no proper controlled group, no controlled environment or noise (26), and a short duration of yoga practices (1-2 h/day) (21-24). Whereas in this study, we had a large sample size $(n=210$ in yoga and equal participants in controlled group) with controlled environment and comparably long duration of intervention as mentioned above.

The trail making task evaluates fine motor coordination, visual-motor integration, visual perception, and cognitive planning ability (36). Our study reflects the positive effects of yoga on academic performance, processing speed, and attention in school children. It was reported earlier that yoga practice improves ability of the individual to control visual distraction leading to increased ability for prepotent inhibition or orientational processing (orients to specific objects in the attentional field) (37) and reduces planning time and improves execution time (7). This effect could be a major factor for lowering time duration for matching alphabets with relevant numbers implying that automatic-response generation was lower in the yoga group compared with control group in this study. Electroencephalography (EEG) (38) and functional magnetic imaging (39) studies implicated frontal lobe activation during performance of TMT and while matching component of alternating letters of the alphabets and consecutive numbers activated the left dorsolateral prefrontal cortex, precentral gyrus, cingulate gyrus and medial frontal gyrus, and supplementary motor area, which are sensitive to executive functioning (40). These neuroimaging studies suggest that the improvement in the performance of TMT in this study may be due to the improvement of frontal lobe activation in school children following 10 days of intense yoga practice. Another study reported that a short-term yogic practice was associated with a physiological relaxation responses (41), leading to enhanced performance speed on color naming (42), decreased automatic responses $(43,44)$, and reaction time involving an attentional task (45-48) suggest yoga may enhances parasympathetic dominance with improved frontal lobe activation.

Yoga brings about positive changes in behavior and mental health of school children $(24,49)$. The results of this study are in accordance with the earlier findings indicating a significant relationship of self-efficacy with academic achievements (50). Yoga practices in this study showed positive changes toward the three domains of self-efficacy, i.e., academic domain, social domain, emotional domain, and overall total domain. The social self-efficacy pertains to children's capability to deal with social challenges, academic self-efficacy refers to children's perceived capability to master academic affairs, and self-regulatory efficacy deals with children's capability to resist peer pressure to engage in high risk activities (51). Mindfulness-based mental training study showed reduced level of stress and enhances mindfulness self-efficacy awareness and attention training, and positive states of mind (52). Similarly, this training also testified lowering of psychological distress, such as tension-anxiety, 
confusion-bewilderment, fatigue-inertia, and vigor-activity parameters in medical students (53). Further studies on yoga practices showed improvement in greater awareness of the feelings associated with stress, and it may enhance coping abilities possibly as part of the process of developing mindfulness or related to cognitive, emotional, or social development $(23,54,55)$. This leads to academic performance, alertness, and academic excellence that are concerned with the quantity and quality of learning attained with yoga or mental training intervention. The academic performance and alertness in school children was high who practiced yoga and reported low stress in children (56). The regular practice of yoga can improve Sattva Guna (balanced personality trait) among students paving the way for their academic excellence. The academic excellence is essential to provide opportunities for students to work together to improve their understanding of concepts in their academic core that helps students to train problem solving and collaborative learning strategies (6). Another major component for higher academic performance is better planning ability with self-regulatory behavior (57). Studies suggest that yoga-based education program improve planning and execution skills in school boys (58). In addition to this, the beneficial effects of meditation on middle school children showed an increased state of restful alertness and greater capacity for self-reflection, self-control, and flexibility as well as improved academic performance that may facilitate the growth of social-emotional capacities necessary for regulating the emotional labiality and interpersonal stress of adolescence (59).

The findings of this study extended previous research on either self-efficacy or psychomotor performance in children, which were assessed simultaneously in this study. Yoga group children reported higher self-efficacy particularly in academic, social, and emotional domain with greater improvement in performance of psychomotor skills and executive functions, which require selective attention, concentration, and visual scanning abilities, and reduced the planning and execution time in TMT task.

Evidence-based previous scientific studies supporting the findings of the preset study on the effect of yogic practices on psychological, behavioral, and cognitive abilities in children are given in Figure 1. Yoga practices reduce visual, audio, and mental distractions, which helps in reducing stress and anxiety in children. Once mental distraction reduced, the mental abilities will be increased with the improvement in their behavioral skills.

The findings of this study are interesting and straightforward, and the study has a major limitation in the selection of school children that was not random in the control group because of

\section{REFERENCES}

1. Bandura A. Self-efficacy: toward a unifying theory of behavioral change. Psychol Rev (1977) 84:191-215. doi:10.1037/0033-295X.84.2.191

2. Bandura A, Cervone D. Differential engagement of self-reactive influences in cognitive motivation. Organ Behav Hum Decis Process (1986) 38:92-113. doi:10.1016/0749-5978(86)90028-2

3. Caprara GV, Gerbino M, Paciello M, Di Giunta L, Pastorelli C. Counteracting depression and delinquency in late adolescence. Eur Psychol (2010) 15:34-48. doi:10.1027/1016-9040/a000004



unavailability of non-yoga practitioner children in the yoga institute. There was also no follow-up, and so, it is not known whether improvements in test performance and self-efficacy are sustained. Despite of aforementioned limitations, the results of our study suggest that yoga-based intervention in school children can improve attention, motor function, and different domains of personality. Initial research on the usefulness of yoga for children and adolescents is promising, more systematic studies including long-term randomized controlled trials (RCTs) with follow-up and active control groups are needed.

\section{AUTHOR CONTRIBUTIONS}

All authors listed have made substantial, direct, and intellectual contribution to the work and approved it for publication.

\section{SUPPLEMENTARY MATERIAL}

The Supplementary Material for this article can be found online at http://journal.frontiersin.org/article/10.3389/fped.2016.00062

4. Thomasson P, Psouni E. Social anxiety and related social impairment are linked to self-efficacy and dysfunctional coping. Scand J Psychol (2010) 51:171-8. doi:10.1111/j.1467-9450.2009.00731.x

5. Deshpande S, Nagendra HR, Nagarathna R. A randomized control trial of the effect of yoga on gunas (personality) and self esteem in normal healthy volunteers. Int J Yoga (2009) 2:13-21. doi:10.4103/09736131.43287

6. Tikhe SG, Nagendra HR, Tripathi N. Ancient science of yogic life for academic excellence in university students. Anc Sci Life (2012) 31:80-3. doi:10.4103/0257-7941.103179 
7. Manjunath NK, Telles S. Improved performance in the Tower of London test following yoga. Indian J Physiol Pharmacol (2001) 45:351-4.

8. Telles S, Hanumanthaiah B, Nagarathna R, Nagendra HR. Improvement in static motor performance following yogic training of school children. Percept Mot Skills (1993) 76:1264-6. doi:10.2466/pms.1993.76.3c.1264

9. Naveen KV, Nagarathna R, Nagendra HR, Telles S. Yoga breathing through a particular nostril increases spatial memory scores without lateralized effects. Psychol Rep (1997) 81:555-61. doi:10.2466/PR0.81.6.555-561

10. Dash $\mathrm{M}$, Telles S. Yoga training and motor speed based on a finger tapping task. Indian J Physiol Pharmacol (1999) 43:458-62.

11. Telles S, Nagarathna R, Vani PR, Nagendra HR. A combination of focusing and defocusing through yoga reduces optical illusion more than focusing alone. Indian J Physiol Pharmacol (1997) 41:179-82.

12. Telles S, Singh N, Balkrishna A. Finger dexterity and visual discrimination following two yoga breathing practices. Int J Yoga (2012) 5:37-41. doi:10.4103/0973-6131.91710

13. Lawrence D, Paul C. The Complete Guide to Yoga for Fitness Professionals. London: Bloomsbury Publishing (2014).

14. Reitan RM. Validity of the Trail Making Test as an indicator of organic brain damage. Percept Mot Skills (1958) 8:271-6.

15. Muris P. A brief questionnaire for measuring self-efficacy in youths. J Psychopathol Behav Assess (2001) 23:145-9. doi:10.1023/A:1012783504852

16. Lezak MD, Howieson DB, Loring DW. Neuropsychological Assessment. 4th ed. New York: Lezak MD (2004).

17. Schunk DH. Self-efficacy and achievement behaviors. Educ Psychol Rev (1989) 1:173-208. doi:10.1007/BF01320134

18. Telles S, Raghavendra BR, Naveen KV, Manjunath NK, Kumar S, Subramanya P. Changes in autonomic variables following two meditative states described in yoga texts. J Altern Complement Med (2013) 19:35-42. doi:10.1089/acm.2011.0282

19. Koenig KP, Buckley-Reen A, Garg S. Efficacy of the get ready to learn yoga program among children with autism spectrum disorders: a pretest-posttest control group design. Am JOccup Ther (2012) 66:538-46. doi:10.5014/ ajot.2012.004390

20. Hagins M, Haden SC, Daly LA. A randomized controlled trial on the effects of yoga on stress reactivity in 6th grade students. Evid Based Complement Alternat Med (2013) 2013:607134. doi:10.1155/2013/607134

21. Mehta S, Shah D, Shah K, Mehta S, Mehta N, Mehta V, et al. Peer-mediated multimodal intervention program for the treatment of children with ADHD in India: one-year followup. ISRN Pediatr (2012) 2012:419168. doi:10.5402/2012/419168

22. Streeter CC, Whitfield TH, Owen L, Rein T, Karri SK, Yakhkind A, et al. Effects of yoga versus walking on mood, anxiety, and brain GABA levels: a randomized controlled MRS study. J Altern Complement Med (2010) 16:1145-52. doi:10.1089/acm.2010.0007

23. White LS. Reducing stress in school-age girls through mindful yoga. J Pediatr Health Care (2012) 26:45-56. doi:10.1016/j.pedhc.2011.01.002

24. Berger DL, Silver EJ, Stein RE. Effects of yoga on inner-city children's wellbeing: a pilot study. Altern Ther Health Med (2009) 15:36-42.

25. Booth JR, Burman DD, Meyer JR, Lei Z, Trommer BL, Davenport ND, et al. Neural development of selective attention and response inhibition. Neuroimage (2003) 20:737-51. doi:10.1016/S1053-8119(03)00404-X

26. Prakash R, Dubey I, Abhishek P, Gupta SK, Rastogi P, Siddiqui SV. Long-term Vihangam Yoga meditation and scores on tests of attention. Percept Mot Skills (2010) 110:1139-48. doi:10.2466/pms.110.3c.1139-1148

27. Manna A, Raffone A, Perrucci MG, Nardo D, Ferretti A, Tartaro A, et al. Neural correlates of focused attention and cognitive monitoring in meditation. Brain Res Bull (2010) 82:46-56. doi:10.1016/j.brainresbull.2010.03.001

28. Subramanya P, Telles S. Performance on psychomotor tasks following two yoga-based relaxation techniques. Percept Mot Skills (2009) 109:563-76. doi:10.2466/pms.109.2.563-576

29. Sharma VK, Das S, Mondal S, Goswami U, Gandhi A. Effect of Sahaj Yoga on neuro-cognitive functions in patients suffering from major depression. Indian J Physiol Pharmacol (2006) 50:375-83.

30. Chambers R, Lo BCY, Allen NB. The impact of intensive mindfulness training on attentional control, cognitive style, and affect. Cognit Ther Res (2007) 32:303-22. doi:10.1007/s10608-007-9119-0

31. Telles S, Nagarathna R, Nagendra HR, Desiraju T. Physiological changes in sports teachers following 3 months of training in yoga. Indian J Med Sci (1993) 47:235-8.
32. Greenberg MT, Harris AR. Nurturing mindfulness in children and youth: current state of research. Child Dev Perspect (2012) 6:161-6. doi:10.1111/ j.1750-8606.2011.00215.x

33. Manjunath NK, Telles S. Factors influencing changes in tweezer dexterity scores following yoga training. Indian J Physiol Pharmacol (1999) 43:225-9.

34. Naranjo JR, Schmidt S. Is it me or not me? Modulation of perceptual-motor awareness and visuomotor performance by mindfulness meditation. BMC Neurosci (2012) 13:88. doi:10.1186/1471-2202-13-88

35. Pradhan B, Nagendra HR. Normative data for the letter-cancellation task in school children. Int J Yoga (2008) 1:72-5. doi:10.4103/0973-6131.43544

36. Halpern J, Cohen M, Kennedy G, Reece J, Cahan C, Baharav A. Yoga for improving sleep quality and quality of life for older adults. Altern Ther Health Med (2014) 20:37-46.

37. Chan D, Woollacott M. Effects of level of meditation experience on attentional focus: is the efficiency of executive or orientation networks improved? J Altern Complement Med (2007) 13:651-7. doi:10.1089/acm.2007.7022

38. Segalowitz SJ, Unsal A, Dywan J. CNV evidence for the distinctiveness of frontal and posterior neural processes in a traumatic brain-injured population. J Clin Exp Neuropsychol (1992) 14:545-65. doi:10.1080/01688639 208402844

39. Moll J, de Oliveira-Souza R, Moll FT, Bramati IE, Andreiuolo PA. The cerebral correlates of set-shifting: an fMRI study of the trail making test. Arq Neuropsiquiatr (2002) 60:900-5. doi:10.1590/S0004-282X2002000600002

40. Zakzanis KK, Mraz R, Graham SJ. An fMRI study of the trail making test. Neuropsychologia (2005) 43:1878-86. doi:10.1016/j.neuropsychologia.2005. 03.013

41. Singh Y, Sharma R, Talwar A. Immediate and long-term effects of meditation on acute stress reactivity, cognitive functions, and intelligence. Altern Ther Health Med (2012) 18:46-53.

42. Foris D. The effect of meditation. J Undergrad Res (2005) 8:1-4.

43. Bhargava R, Gogate MG, Mascarenhas JF. Autonomic responses to breath holding and its variations following pranayama. Indian J Physiol Pharmacol (1988) 32:257-64.

44. Telles S, Raghavendra BR, Naveen KV, Manjunath NK, Kumar S, Subramanya P. Changes in autonomic variables following two meditative states described in yoga texts. JAltern Complement Med (2013) 19:35-42. doi:10.1089/ acm.2011.0282

45. Telles S, Nagarathna R, Nagendra HR. Autonomic changes during "OM" meditation. Indian J Physiol Pharmacol (1995) 39:418-20.

46. Pradhan B, Nagendra H. Immediate effect of two yoga-based relaxation techniques on attention in children. Int J Yoga (2010) 3:67-9. doi:10.4103/ 0973-6131.72632

47. Luders E, Kurth F, Mayer EA, Toga AW, Narr KL, Gaser C. The unique brain anatomy of meditation practitioners: alterations in cortical gyrification. Front Hum Neurosci (2012) 6:34. doi:10.3389/fnhum.2012.00034

48. Telles S, Singh N, Bhardwaj AK, Kumar A, Balkrishna A. Effect of yoga or physical exercise on physical, cognitive and emotional measures in children: a randomized controlled trial. Child Adolesc Psychiatry Ment Health (2013) 7:37. doi:10.1186/1753-2000-7-37

49. White LS. Yoga for children. J Pediatr Nurs (2009) 35:277-83, 295.

50. Tenaw Y. Relationship between self-efficacy, academic achievement and gender in analytical chemistry at Debre Markos College of teacher education. Afr J Chem Educ (2013) 3:3-28.

51. Muris P. Measure - the self-efficacy questionnaire for children. J Psychoeduc Assess (2007) 25:341-55. doi:10.1177/0734282907300636

52. Chang VY, Palesh O, Caldwell R, Glasgow N, Abramson M, Luskin F, et al. The effects of a mindfulness-based stress reduction program on stress, mindfulness self-efficacy, and positive states of mind. Stress Heal (2004) 20:141-7. doi:10.1002/smi.1011

53. Rosenzweig S, Reibel DK, Greeson JM, Brainard GC, Hojat M. Mindfulnessbased stress reduction lowers psychological distress in medical students. Teach Learn Med (2003) 15:88-92. doi:10.1207/S15328015TLM1502_03

54. Smith JA, Greer T, Sheets T, Watson S. Is there more to yoga than exercise? Altern Ther Health Med (2011) 17:22-9.

55. Melville GW, Chang D, Colagiuri B, Marshall PW, Cheema BS. Fifteen minutes of chair-based yoga postures or guided meditation performed in the office can elicit a relaxation response. Evid Based Complement Alternat Med (2012) 2012:501986. doi:10.1155/2012/501986 
56. Kauts A, Sharma N. Effect of yoga on academic performance in relation to stress. Int J Yoga (2009) 2:39-43. doi:10.4103/0973-6131.53860

57. Tseng MH, Chow SM. Perceptual-motor function of school-age children with slow handwriting speed. Am JOccup Ther (2000) 54:83-8. doi:10.5014/ ajot.54.1.83

58. Rangan R, Nagendra HR, Bhat GR. Planning ability improves in a yogic education system compared to a modern. Int J Yoga (2008) 1:60-5. doi:10.4103/0973-6131.41033

59. Rosaen C, Benn R. The experience of transcendental meditation in middle school students: a qualitative report. Explore (NY) (2006) 2:422-5. doi:10.1016/j.explore.2006.06.001
Conflict of Interest Statement: The authors declare that the research was conducted in the absence of any commercial or financial relationships that could be construed as a potential conflict of interest.

Copyright (C) 2016 Das, Deepeshwar, Subramanya and Manjunath. This is an open-access article distributed under the terms of the Creative Commons Attribution License (CC BY). The use, distribution or reproduction in other forums is permitted, provided the original author(s) or licensor are credited and that the original publication in this journal is cited, in accordance with accepted academic practice. No use, distribution or reproduction is permitted which does not comply with these terms. 